\title{
VISIT TO THE SCIENCE COLLECTIONS, SOUTH KENSINGTON.
}

\author{
Saturday, April 10th, 1886. \\ (By permission of the Science and Art Department.) \\ Director : Prof. J. W. Jodd, F.R.S., Pres. G.S. \\ (Report by The DiRector.)
}

These collections are designed to illustrate $(a)$ the history of scientific discovery; $(b)$ the instruments and apparatus employed in scientific research ; $(c)$ the appliances useful for scientific instruction. When fully developed the Science Museum will occupy much the same place as the Conservatoire des Arts et Métiers does among the educational institutions of Paris.

The collections of the museum illustrate the mathematical and physical sciences, chemistry, biology, geology, and mineralogy, and geography and meteorology ; but on this occasion the attention of the visitors was particularly directed to the exhibits which had a bearing on some branch or other of geological science, and short demonstrations were given on the following subjects :-

1. The self-registering (Six's) thermometers, used on board H.M.S. "Challenger," for determining the temperature of the ocean at different depths. The manner in which some of these had been broken and crushed by the pressure at great depths was illustrated.

2. The instruments actually employed in the Ordnance Survey of the British Isles, namely :-

a. Colby's compensation bars.

b. Airy's zenith sector.

c. Various theodolites.

The methods of measuring and checking the base line, used for the primary triangulation of the British Isles, were illustrated by maps and diagrams.

3. Apparatus for deep-sea soundings used in the different expeditions which have been organized by the British Government for surveying the ocean floor.

4. Geological maps, models, and photographs.

5. Different forms of seismoscopes, seismometers, and seismographs. 
6. Mr. C. J. Woodward's apparatus for illustrating the formation of volcanic cinder-cones, and Dr. E. Keyers' illustration of the formation of lava-cones.

7. Different forms of apparatus employed in cutting rocks and minerals, and in preparing thin sections of the same for microscopical study.

8. Petrographical microscopes of different patterns, with appliances required in the modern methods of petrographical research. Among these were shown the microscopes designed by Prof. Rosenbusch, of Heidelberg, and Prof. Klein, of Gottingen, and also the ingenious microscope of M. Nachet, of Paris, in which perfect centring is secured. Goniometers, reflectometers, dichroiscopes, polariscopes, stauroscopes, and other pieces of apparatus used in mineralogical research, including the "Universal-apparat" of Groth, were also exhibited.

9. Jordan's glycerine barometer was shown, and its readings compared with that of a standard mercurial barometer.

10. Foucault's pendulum for demonstrating the fact of the earth's rotalion was shown in action, together with the gyroscope employed for the same purpose.

11. A short lecture was given by the Director on some of the chief varieties of vitreous rocks, including Fulgurite, Marekanite, Boutellenstein, and various forms of obsidian and pitchstone. Different kinds of devitrificative products, including spherulitic, banded, fluidal and other structures, and the formation of pumice. Pélé's hair and similar materials were illustrated, as was also the formation of perlitic structures, and the origin of stain phenomena in natural glasses, whereby they acquire the power of depolarizing light. A large series of sections illustrating these phenomena were placed under microscopes for the inspection of the visitors.

\section{VISIT TO THE MUSEUM OF THE ROYAL COLLEGE OF SURGEONS, LINCOLN'S-INN-FIELDS. Saturday, April $17 \mathrm{mH}, 1886$.}

Demonstration on Pterosauria, \&c., by Professor Chances Stewant, F.L.S., Curator of the Museum. 